\title{
FREQUENCY OF BETA-THALLASSEMIA TRAIT AMONG PREGNANT WOMEN IN THEIR LAST TRIMESTER WITH HYPOCHROMIC MICROCYTIC ANEMIA
}

\author{
Hamzullah Khan ${ }^{1}$, Fareedullah Shah², Khalid Khan ${ }^{3}$
}

${ }^{1}$ Assistant Professor, Department of Hematology, Nowsher Medical College Nowshera.

${ }^{2}$ Department of Paediatrics Lady Reading Hospital Peshawar.

${ }^{3}$ Khyber Medical University, M.Phil Supervisor.

Correspondence: Hamzullah Khan. Cell: 0334-4802902, E-mail: hamzkmc@gmail.com

\begin{abstract}
Background: Beta-Thalassaemia is a public health issue. Generally, very few people know about it in detail. Due to ignorance, government bear tremendous financial cost to care for it.

Methods: This was a cross sectional observational study conducted in an outdoor patient department (OPD) of Gynecology and obstetrics of a Postgraduate Medical Institute at Peshawar, from August 2012 to Jan 2013. A Total of 56 women in their last trimester of pregnancy were included. Required information's were recorded on predesigned proforrma as per objectives of the study.

Results: Most of the participants were of age 20 to 49 years with mean+ SD of 34+3.4years. Majority (87.5\%) of the Red Blood Cell (RBC) count was equal or less than $4600000 / \mathrm{cmm} 3$. A few (12.5\%) of the participants had their RBC count more than $4600000 / \mathrm{cmm} 3$. More than two-thirds $(76.79 \%)$ had RDW (Red Cell Width Distribution SD) below $45 \%$, while less $(20.21 \%)$ had RDW more than $45 \%$. The seven cases that had high RBC count underwent $\mathrm{Hb}-$ Electrophoresis where in two cases (3.2\%) were reported to be ? -thalssaemia trait.

Conclusion: Majority of the patient were having low RBC count that needed further investigations i.e Serum Ferritin to confirm the iron deficiency. Similarly those who have had high RBC count when subjected to Hb-electrophoresis, showed B.thallassemia trait. We suggest all those cases having RBC count more than $4600000 / \mathrm{cmm} 3$ and RDW-SD less than $45 \%$ may further be screened for thalssaemia trait, that may help to counselling families for future.
\end{abstract}

Keywords: Thalassemia, blood disorder, low and middle income country.

\section{Introduction}

Pakistan has a population of 180 million plus people. Five percent of our country population carry betathalassaemia gene, and 0.5 to $1 \%$ carry $\mathrm{Hb} \mathrm{S}$ and $\mathrm{Hb} \mathrm{E}$ type genes on haemoglobin. The infants affected by Beta trait (BTT) are at a rate of 1.3 per 1000 live births, and about 6,000 to 7,000 children are born annually with beta-thalassaemia. Unfortunately, majority of the people are unaware of the disease, and a minimum of these cases are correctly diagnosed. Out of the affected cases, $80 \%$ of the thalassemia patients die due cardiac failure and iron overload, and transfusion related risks. Thalassemia is controlled by parental screening for trait, and by haemoglobin electrophoresis before marriages in couples with high risk of having children with thalassaemia $(1,2)$.

It is reported that 5000 to 9000 of the children with Beta-thalassemia born each year in Pakistan. There are 9.8 million carriers of thalassaemia with a BTT rate of $5-7 \%$ in the country $(3,4)$. Another study reported that around eight million Pakistanis are suffering from BetaThalassemia trait. Modell and Darlinson reported it as
4.6\% in Pakistan during 2008(5). In our scenario a weak infrastructure of health care facilities and very few screening facilities for screening of BTT and cultural trends of cousin marriages of approximately $40 \%$ in our societies leads to high risk of Beta-Thalassemia trait (6).

Pakistan is a country with racial mix and a nation of considerable genetic diversity. Cultural preferences are stronger for consanguineous marriage that is high risk factor for prevalence of recessive disorders like Beta-thalassemia. To let these children healthy Betathalassemia patients require monthly blood transfusions along with iron-chelation therapy. To treat one annual birth cohort of thalassemia we need 90,000 blood units and 22 million dollars for deferoxamine for chelation therapy (7).

A study on the screening for Beta thalassemia trait in pregnancy, concluded that carrier screening for thalassemia should be done on all pregnant women attending antenatal clinics (8). Another national study on the frequency of Beta thalassemia trait in pregnant women reported prevalence of $8.5 \%$. $17.6 \%$ cases husbands were also trait (9). 
Present study was conducted to determine frequency of b-thallassemia trait in pregnant women in their last trimester with hypochromic microcytic anemia.

\section{Methodology}

This cross sectional study conducted in gynecology and obstetrics department of MTI, Lady reading Hospital Peshawar, from Aug 2012 to Jan 2013. Samples were collected via convenient (Non-Probability) sampling. A total of 56 women in their third trimester were enrolled. Inclusion criteria were all patients irrespective of age, or cause for attending the OPD. All patients taking regular iron therapy for anemia, and post-natal cases with other gynecological disorders were excluded. Patients with RBC count $>4600000 / \mathrm{cmm} 3$ were subjected to $\mathrm{Hb}$ Electrophoresis for b-Thallassemia trait.. Patients with RBC $<4600000 / \mathrm{cmm} 3$ were not subjected to $\mathrm{Hb}$ Electrophoresis. Blood samples taken from all patients. $3 \mathrm{ml}$ of venous blood was collected by veine-puncture under aseptic techniques using disposable syringes. The blood was added to EDTA tubes and mixed gently. Complete blood picture was with hematology analyzer taken in the laboratory of Institute of basic medical sciences (IBMS) Khyber Medical University.

For $\mathrm{Hb}$-Electrophoresis, hemolysate was prepared adding carbon tetrachloride to remobve all other globin other than HB and distilled water also added. $\mathrm{Hb}$ electrophoresis done using Wealtech, machine, USA. Current flow of machine was adjusted as per instruction of the manual of device. Cellulose acetate strip was used for application of hemolysate and different bands of hemoglobin were recorded for reporting. Similarly the preliminary information's of the women regarding, age, gravida, para, address, weight and socioeconomic status were recorded on the questionnaire. The data was analyzed using MS-Excel program for outcome.

\section{Results}

A total of 56 women in their third trimester presenting to Gynecology and obstetrics department of Lady reading hospital Peshawar. The age range of the patient was from 20 years to 49 years with mean age of $34+3.4$ years (Table 1). RBC count of $87.50 \%$ was equal or less than $4600000 / \mathrm{cmm} 3$. Seven(12.5\%) of the women had their RBC count more than $4600000 / \mathrm{cmm} 3$ (Table 2). $76.79 \%$ had RDW(Red Cell Width Distribution SD) below $45 \%$, while $20.21 \%$ had RDW more than $45 \%$ Table 3. The seven cases that had high RBC count underwent $\mathrm{Hb}$-Electrophoresis where in two cases (3.2\%) were reported to be b-thalssemia trait (Table 4 ).

\section{Table 1. Age range of patients.}

\begin{tabular}{|l|l|l|}
\hline Age & Total & Percentage \\
\hline $23-32$ & 29 & 51.79 \\
\hline $33-42$ & 20 & 35.71 \\
\hline $43-52$ & 6 & 10.71 \\
\hline $53-62$ & 1 & 1.79 \\
\hline Grand Total & 56 & \\
\hline
\end{tabular}

Table 2. Red Cell count of the respondents

\begin{tabular}{|l|l|l|}
\hline RBC(/UL) & Total & PERCENTAGE \\
\hline $3010000-3809999$ & 18 & 32.14 \\
\hline $3810000-4609999$ & 31 & 55.36 \\
\hline $4610000-5409999$ & 7 & 12.5 \\
\hline Grand Total & 56 & \\
\hline
\end{tabular}

Table 3. Red Cell Width Distribution range.

\begin{tabular}{|l|l|l|}
\hline RDW-SD(fl) & Total & Percentage \\
\hline $17-26$ & 1 & 1.79 \\
\hline $37-46$ & 42 & 75.00 \\
\hline $47-56$ & 10 & 17.86 \\
\hline $57-66$ & 2 & 3.57 \\
\hline $67-76$ & 1 & 1.79 \\
\hline Grand Total & 56 & \\
\hline
\end{tabular}

Table 4. Hb. Electrophoresis Reports of the target cases.

\begin{tabular}{|l|l|l|}
\hline $\begin{array}{l}\text { HB. Electrophoresis } \\
\text { Report }(7 / 56)\end{array}$ & $\begin{array}{l}\text { Number of patients } \\
(7 / 56)\end{array}$ & Percentage \% \\
\hline Normal & 5 & 8.92 \\
\hline B- Thalassemia Trait & 2 & 3.5 \\
\hline Total & $7(56)$ & \\
\hline
\end{tabular}

\section{Discussion}

Thalassemia incidence globally is very high, nearly 30 million people are reported with with beta thalassemia trait. BTT incidence differs from 3 to $17 \%$ globally. This creates heavy burden on the society in terms of finance and social liabilities. One of th reduce the burden o most effective strategy to reduce the incidence of thallasemia is the implementation of carrier screening program especially among the pregnant ladies, genetic counseling, prenatal diagnosis of BTT and dsiease and therapeutic abortion or termination of pregnancies for the affected fetuses (10). Early diagnosis of Betathalassemia trait is necessary for two reasons; one is differentiation from iron deficiency and second is for genetic counseling if there is affected fetus. In Pakistan the BTT rate is $8-10 \%$ (11). There are over 4000 thalassemia children born in Pakistan yearly and the available infrastructure and health care facilities are not sufficient to deal with this number of children. If we start screening for these cases about $70 \%$ of hidden carriers can be diagnosed just by knowing percentage of $\mathrm{HbA} 2$ by electrophoresis. There is need for to raise public awareness and to encourage people to go diagnose for screening of trait and to diagnosis risk of thalassemia major off spring and to avoide trait to trait marriages as seen in consanguinity marriages (12). We don't discourage cousin marriages but we discourage trait to trait marriages.

The microcytic hypochromic anemia can be either beta thalassemia trait (Beta-TT) or iron deficiency anemia (IDA). In present study RBC count of $87.50 \%$ respondents was equal or less than $4600000 / \mathrm{cmm} 3$. Seven $(12.5 \%)$ of the women had their RBC count more than $4600000 / \mathrm{cmm} 3$. These patients were then selected 
for $\mathrm{Hb}$-Electrophoresis. Another study also reported that $\mathrm{RBC}$ count is lowest in cases of Beta thalassemia major and highest in Beta thalassemia minor or trait (13). So these high counts candidates were subjected to electrophoresis test for know their status for Beta.Thallassemia trait.

We evaluated patients according to red blood cell (RBC) count and red blood distribution width indices. In our study $76.79 \%$ had RDW(Red Cell Width Distribution-SD) below $45 \%$, while $20.21 \%$ had RDW more than $45 \%$ which is not specific for differentiating IDA from Beta thallassemia trait, so we recommend Serum Ferritin level along with $\mathrm{Hb}$-Electrophoresis to differentiate between the two disorders. A raised RBC count > 5.0 106/uL is a common feature of BetaThalassemia trait. The high RBC count is one of the accurate indices of Beta Thallassemia trait. It provides best sensitivity for Beta Thallassemia trait $(94.8 \%)(13)$. RBC count has been considered a valuable index for further investigating a patient for b-thalassemia trait (14). But few other studies report that RBC count $>5.0 \times$ 106/BetaL helps you diagnosis of Beta Thallassemia trait. But in IDA the frequency of raised RBC count was $29.4 \%$ as compared to Beta-TT. This confirms that only RBC count alone was not a reliable indicator for distinguishing Beta-TT from IDA. Elevated RBC count may be associated with other conditions like erythrocytosis. Same findings reported by Aslan and Altay, they reported a high RBC count in $61 \%$ of cases with iron deficiency anemia(13-15).

In present study the seven cases that had high $\mathrm{RBC}$ count underwent $\mathrm{Hb}$-Electrophoresis where in two cases $(3.2 \%)$ were reported to be Beta Thallassemia trait out of the total sampling. Our finding correlates with other national studies where they reported a carrier rate of $5-7 \%$ in Pakistan $(3,4)$. Another study reported that national Beta-thalassaemia trait rate of $4.6 \%$ in Pakistan5.

In conclusion we found that a high RBC count in pregnancy status must be evaluated further for thassemia trait by doing HB-electrophoresis or high performance liquid chromatography. We suggest all those cases having RBC count more than $4600000 / \mathrm{cmm} 3$ and RDW-SD less than $45 \%$ may further be screened for B-Thallassemia trait, as these are the target group where if we further proceed with $\mathrm{Hb}$ Electrophoresis, we can find out b-Thassemia trait well in time and can help to counsel families on marriage and pregnancy status. We again insist on statement that trait should not marry trait its always not cousin marriages.

\section{References}

1. Farzana, F., Zuberi, Si. and Haahmi, ).A. Prevalence of abnormal haemoglobin and thalaaaemia trait inEroup of professional blood donors and hospital staff in Karachi. 3. Pat Med. Assoc., 1986;36:11-15.

2. Abolghasemi H, Amid A, Zeinali S, Radfar $\mathrm{MH}$, Eshghi P, Rahiminejad MS, et al. Thalassemia in
Iran: epidemiology, prevention, and management. J Pediatr Hematol Oncol 2007;29:233-8

3. Ansari SH, Shamsi TS, Ashraf M, Bohray M, Farzana T, Khan MT, et al. Molecular epidemiology of Beta- thalassaemia in Pakistan: Far reaching implication. Int J Mol Epidemiol Genet 2011;2:403-8.

4. Black ML, Sinha S, Agarwal S, Colah R, Das R, Bellgard $M$, et al. A descriptive profile of Betathalassaemia mutations in India, Pakistan and Sri Lanka. J Community Genet 2010;1(3):14957.

5. Modell B, Darlinson M. Global epidemiology of haemoglobin disorders and derived service indicators. Bull World Health Organ 2008;86:480-7.

6. Ahmed S, Saleem M, Modell B, Petrou M. Screening extended families for genetic haemoglobin disorders in Pakistan. $\mathrm{N}$ Engl J Med 2002;347:1162-8.

7. Ahmed S, Saleem M, Modell B, Petrou M. Screening extended families for genetic hemoglobin disorders in Pakistan. N Engl J Med. 2002;347:1162-8.

8. Baxi A, Manila K, Kadhi $P$ et al.Carrier Screening for Beta Thalassemia in Pregnant Indian Women: Experience at a Single Center in Madhya Pradesh. Indian J Hematol Blood Transfus. 2013; 29(2): 71-74.

9. Nisa QU, Habibullah, Rizwan F et al. Frequency of thalassemia trait in pregnant women. Medical Channel,2011;17:55-57.

10. Modell B, Bulzhenov V. Distribution and control of some genetic disorders. World Health Stat. 1988;41:209-18.

11. Anjum S, Tayyab M, Shah SM, Choudry N. Detection of thalassemia Trait. A study of 50 families. J Ayub Med Eoll Abbatabad, 2001; 13:113.

12. Khateeb B, Moatter T, Shagil AM, Haroon S, Kakapoto GN. Genetic Diversity of bThalassemia Mutations in Pakistani Population. Vol.50, No 9, September, 2000:293-6.

13. Mehdi SR, Al-Dahmash BA. A comparative study of hematological parameters of Beta and Beta thalassemias in a high prevalence zone: Saudi Arabia. Indian J Hum Genet. 2011,17(3): 207-11.

14. Demir A, Yaral N, FBetasgBetan T, Duru F, Kara A. Most reliable indices in differentiation between thalassemia trait and iron deficiency anemia. Pediatrics International, 2002; 44(6):612-6,

15. Aslan D, Altay Ç. Incidence of high erythrocyte count in infants and young children with iron deficiency anemia: re-evaluation of an old parameter. Journal of Pediatric Hematology/Oncology,2003; 25: 303-6. 